\title{
The Manufacture of Fine Paper in England in the Eighteenth Century.
}

THE MS. correspondence of Conyers Middleton with Lord Hervey, acquired by the British Museum in 1885 , contains, incidentally, evidence respecting the source from which fine paper, suitable for printing handsome books, was derived by English publishers until nearly the middle of the eighteenth century. Much of this correspondence relates to the progress of Middleton's Lifo of Cicero, Lord Hervey, to whom the book was dedicated, and who had been zealous in procuring subscribers, frequently urging more expedition, and Middleton assigning various causes for delay. At last, under date of April 6th, 1740, Middleton mentions one which he regards as for the time insuperable. War against Spain, it should be noticed, had been declared in November, 1739, and Spain had at the time troops in Italy, and considerable naval strength in the Mediterranean.

"As to Tully," says Middleton, "I am ashamed almost to mention it, on account of a total cessation of the press from want of paper, occasioned by the uncertain return of ships from Genoa since the commencement of the war, during which our large paper is exhausted, and not a sheet of it to be had in London till a fresh cargo arrives, which is expected, however, every day. The booksellers did not give me the least hint of this till it was too late to be remedied, knowing that it would vex me, as it really has done, yet there is no help but patience. But we may possibly retrieve this loss of time by employing several presses at once as soon as we get paper, since I have now finished all my part, and assure your lordship that there is not a subscriber so desirous to read as I am to get it out of my hands."

On April 27th, Middleton repeats his assurance that " no one is half so impatient to read as I am to publish." This does not satisfy Lord Hervoy, who writes on May 27th: "I cannot, nor ought to conceal from you the general dissatisfaction and mur- 
muring there is among your subscribers a the long delay of the publication of your work. I tell the story of the disappointment you met with in the paper, but am answered by almost everybody that this need not and should not hinder your publishing at least the first volume. I could wish that some way could be contrived, without you or your bookseller running any risk, to let the first part come out immediately. Could you not do it by a previous advertisement relating the misfortune of the paper, and saying whoever was willing to pay the second payment should have the first part delivered to them ?"

Middleton replies on June 3rd : "As to the publication, all I can say is that as soon as paper arrives, your lordship shall be master both of the time and the manner, so far as is in my power, bat antil we get a recruit of paper, which has long been wholly exhausted, it is not possible to publish the first volume, since there are two sections of it still unprinted."

On June i th, however, he reports a change for the better :"Our paper arrived in the Downs last week, and is in port probably by this time, so that we shall now carry on our work with all possible vigour, and if we cannot publish both the volumes in Michaelmas term, which my managers, however, promise me to do, I will undertake at least at all adventures for the publication of the first."

The work still did not progress. Middleton writes on August 24th :- "I should sooner have paid my thanks if I had not been tempted to wait these two or three posts by the daily expectation of being able to send you some good news from the press, but I have the mortification still to acquaint your lordship that we have not printed a sheet since I saw your lordship, and though I wrote to my bookseller above three weeks ago to know what ond we are to expect to this unaccountable interruption, yet I have not heard a word from him."

But on September $4^{\text {th }}$ he reports himself at the end of his troubles, so far as concerns the supply of paper:- "I could not omit the first opportunity of acquainting your lordship that we have received a stock of paper at last from Genoa, sufficient for finishing the first volume, and have provided a quantity also of our oum maxufacture, which is the bottor of the two, for carrying on the socond volume at the same time, which I have ordered to be committed immediately to the press, and hope that we may be able still to publish both the volumes before Christmas."

The bock did, in fact, appear about February, 1741. An 
examination of the copies in the King's and Cracherode Libraries, British Museum, confirm the statements of Middleton's letters. The work is printed on two different qualities and descriptions of paper. By much the larger part of the first volume, extending in the King's Library copy to p. 472, sig. Oo, and in the Cracherode copy to p. 464 (misprinted 264), sig. Nnn, but not including the dedication, preface, or list of subscribers, is impressed on a very fine thick paper, without name, date, or device, except two watermarks, frequently interchanged, resombling respectively an escutcheon and a flowr-do-lis. The remainder of the volume, and the whole of vol. 2, are executed upon a good, but thinner and inferior, paper, with no clue to the date or place of manufacture. The first leaf for which this new paper is employed is greatly stained in both copies, apparently from contact with the Italian paper, as the same is the case with the last leaf of the preliminary matter. Some other leaves are slightly stained, especially near the end. The leaves in finest condition are those of the dedication to Lord Hervey and the preface, which were printed last, and with which especial care would be taken. The portion of the first volume printed on the English paper is not so considerable as Middleton seems to have at one time expected, consisting, instead of two sections, of only a portion of section 6 , the last in the volume. It must be supposed that the paper "in the Downs" proved sufficient to carry the impression on to the point where the Italian paper fails. The difference between the thickness of the two papers is such that although vol. 2 has only $3^{6}$ pages less than vol. I, it weighs II $\frac{1}{2}$ oz. less, or about $\frac{1}{8}$.

It appears unquestionable, then, that about the year $174^{\circ}$ English publishers depended for the execution of fine books upon paper imported from Genoa, and that the interruption of supply from this quarter occasioned great inconvenience for a time, keeping an important book at a standstill for several months, but soon called the manufacture of fine paper into activity as a branch of English industry. It would be interesting to know how long before $\mathrm{r}_{740}$ this trade originated, and how long after that date it continued. It is scarcely likely that it flourished during the warlike times of Queen Anne; it probably grew up during the quarter-century of tranquillity which followed the Treaty of Utrecht. It is not probable that it long survived the development of the manufacture of fine paper in England. Though inferior to the Italian, the English paper was quite 
good enough to displace it if it had the advantage of superior cheapness, as it certainly must have had. Ample materials for deciding these questions probably exist on the shelves of the King's Library.

It should be mentioned that there was an impression of the Life of Cicero on small paper, but the great majority of the splendid list of subscribers prefixed to the work appear as subscribing for large paper copies.

R. GARNETT. 